\title{
Pulmonary epithelioid hemangioendothelioma misdiagnosed as a benign nodule
}

\author{
Minah Kim ${ }^{1}$, Jinsun Chang ${ }^{1}$, Hayoung Choi ${ }^{1}$, In-Jae Oh ${ }^{1,2^{*}}$, Chul-Kyu Park ${ }^{1,2}$, Young-Chul Kim ${ }^{1,2}$, Yoo-Duk Choi ${ }^{2,3}$, \\ Ju-Sik Yun ${ }^{2,4}$, Sang-Yun Song ${ }^{2,4}$ and Kook-Joo Na ${ }^{2,4}$
}

\begin{abstract}
Pulmonary epithelioid hemangioendothelioma (PEH) is a rare vascular tumor of borderline malignancy that originates from endothelial cells. Chest computed tomography (CT) performed during a routine cancer screening revealed multiple small pulmonary nodules in a 50-year-old man who had previously undergone endoscopic submucosal dissection of early gastric cancer. To rule out metastatic nodules, a wedge resection of the left upper lobe was performed and the frozen biopsy reported a benign fibrotic nodule. Using immunohistochemistry, the final pathology was indicated to be PEH, and consecutive surgery for the right-side nodules was planned and performed.
\end{abstract}

Keywords: Epithelioid hemangioendothelioma, Multiple pulmonary nodules, Surgery

\section{Background}

Epithelioid hemangioendothelioma is a rare vascular tumor, originating from endothelial cells, which is histologically characterized by an epithelioid appearance [1]. The term was initially applied by Weiss and Enzinger to a soft tissue vascular tumor of borderline malignancy [2]. Pulmonary epithelioid hemangioendothelioma (PEH) is the currently preferred term for the neoplastic process, which was originally described as intravascular bronchioloalveolar tumor in the lung. Being considered a low to intermediate grade sarcoma, the tumor predominantly involves the liver, lungs, soft tissues, and rarely bones, and can be aggressive and multicentric, even resulting in systemic metastasis [3-5]. PEH typically occurs as bilateral multiple nodules among young women and has a variable clinical course [6].

We describe a case of PEH misdiagnosed as a benign fibrotic nodule from frozen biopsy analysis following video-assisted thoracoscopic surgery (VATS). We performed a consecutive operation for the other nodules

\footnotetext{
* Correspondence: droij@chonnam.ac.kr

'Department of Internal Medicine, Chonnam National University Medical School, 671 Jebong-ro, Dong-gu, Gwangju 501-757, Republic of Korea ${ }^{2}$ Lung and Esophageal Cancer Clinic, Chonnam National University Hwasun Hospital, 322 Seoyang-ro, Hwasun, Jeonnam 519-809, Republic of Korea
} Full list of author information is available at the end of the article after confirming PEH based on the permanent biopsy report.

\section{Case presentation}

A 50-year-old man who visited the hospital every year after endoscopic submucosal dissection of early gastric cancer underwent a chest computed tomography (CT) for cancer screening. The patient was a 50-pack-year current smoker, but he did not have any respiratory or systemic symptoms. The chest CT scan showed small nodules on both sides of the lungs. There was a peripherally located small nodule with lobulation in the apicoposterior segment of the left upper lobe (LUL) and two tiny nodules in the posterobasal segment of the right lower lobe (RLL) (Figure 1). Levels of tumor markers, such as carcinoembryonic antigen and cancer antigen 19-9, were within the normal range. The preoperative forced expiratory volume in $1 \mathrm{~s}$ was $3.02 \mathrm{~L}$ ( $80 \%$ of the predicted value) without an obstructive pattern. Given that the patient was a current smoker, was older than 50 years, and had a gastric cancer history, we decided to perform a surgical biopsy of the nodules.

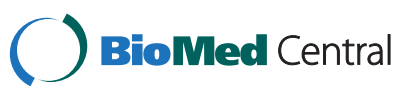

(C) 2015 Kim et al.; licensee BioMed Central. This is an Open Access article distributed under the terms of the Creative Commons Attribution License (http://creativecommons.org/licenses/by/4.0), which permits unrestricted use, distribution, and reproduction in any medium, provided the original work is properly credited. The Creative Commons Public Domain Dedication waiver (http://creativecommons.org/publicdomain/zero/1.0/) applies to the data made available in this article, unless otherwise stated. 


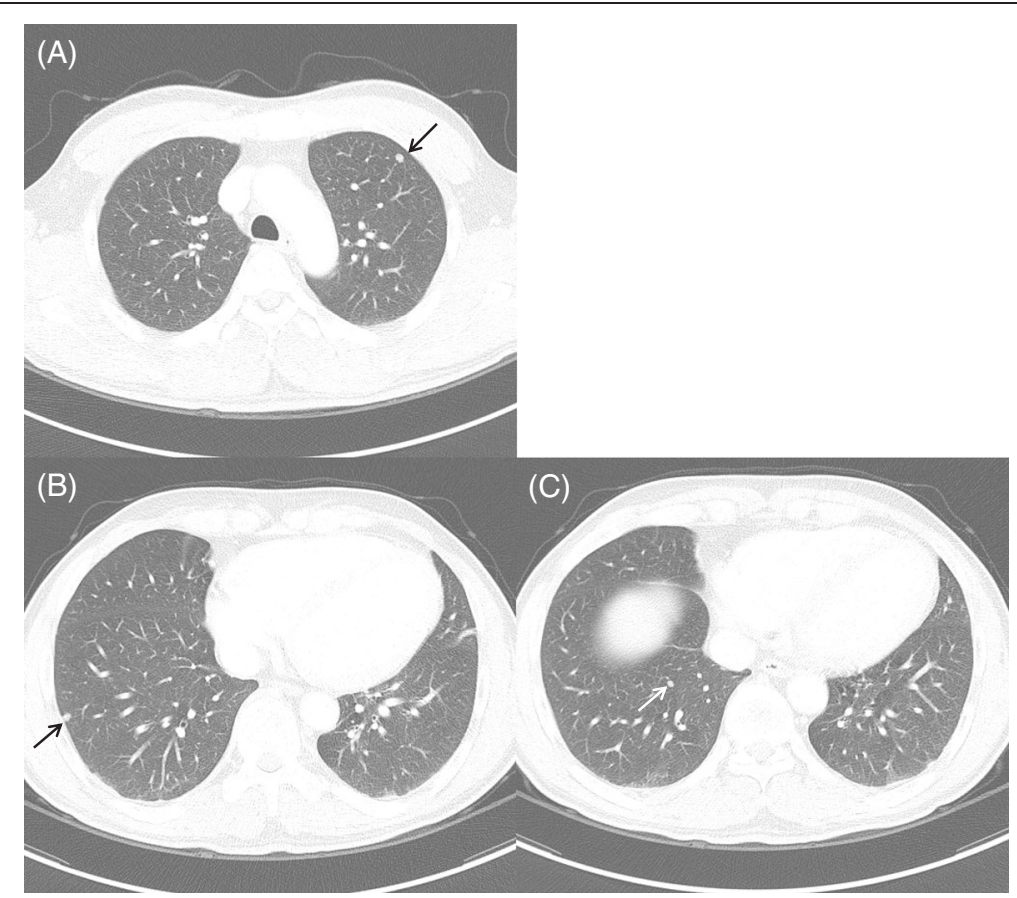

Figure 1 The initial chest computed tomography scan. (A) There is a peripheral small nodule with lobulation in the apicoposterior segment of the left upper lobe (arrow). (B, C) Two tiny nodules are noted in the posterobasal segment of the right lower lobe (arrows).

Under general anesthesia, the surgeons performed a wedge resection by VATS. The LUL nodule was palpable to the finger and was $1 \mathrm{~cm}$ in size, hard, and capsulated in nature. There was no adhesion with the lung parenchyma or pleura. The frozen biopsy showed a hypocellular nodule in a fibrotic stroma. It was reported as a fibrotic nodule. The RLL nodules were also considered as benign because of similar features. A CT follow-up of these nodules was planned rather than surgical resection. Postoperatively, the patient did not show any surgical complications.

The pathological findings of the resected LUL nodule indicated a well-demarcated hypocellular hyalinized nodule. Generally, the neoplastic cells were loosely embedded in hyalinized fibrous stroma individually, although it was more dense cellularly at the periphery of the nodule. The neoplastic cells showed no nuclear atypia and contained variably prominent eosinophilic cytoplasm with or without cytoplasmic vacuoles which was reminiscent of endothelial differentiation. The tumor cells also showed immunoreactivity for CD31 (Figure 2). These features are consistent with the histological characteristics of epithelioid hemangioendothelioma $[7,8]$. We decided to perform consecutive surgery of the two remnant tiny RLL nodules. Given that the preferred locations of epithelioid hemangioendothelioma are the liver and soft tissue, we performed an abdominopelvic CT before the second operation. There was no definite focal wall thickening and no enhanced masses were detected in the intraabdominal organs. The second operation was performed successfully using VATS; the pathological findings of the two tiny nodules were similar to those of the previous LUL nodule. After the second surgery, we performed follow-up chest CTs at 6-month intervals. There has been no evidence of recurrence or other metachronous nodules for 18 months.

\section{Discussion}

Epithelioid hemangioendothelioma is a rare tumor, which mainly affects the liver and, more rarely, the lung. The other organs affected tend to be superficial or deep soft tissues of the extremities. The estimated prevalence of epithelioid hemangioendothelioma is less than 1 in 1 million [9]. Initially known as intravascular bronchioloalveolar tumor [4], PEH is a rare vascular tumor of an indeterminate or low-grade malignancy. PEH affects young people; the median age of onset is 36 years [10]. The incidence is two times higher in women than that in men. Approximately $50 \%$ to $76 \%$ of patients are asymptomatic. Some patients have chest pain, pleuritic pain, cough, dyspnea, or rarely hemoptysis. Although the typical CT findings are multiple small unilateral (23.7\%) or bilateral $(76.2 \%)$ pulmonary nodules, $\mathrm{PEH}$ can also present as multiple pulmonary reticulonodular opacities or diffuse infiltrative pleural thickening. Diagnosis is 


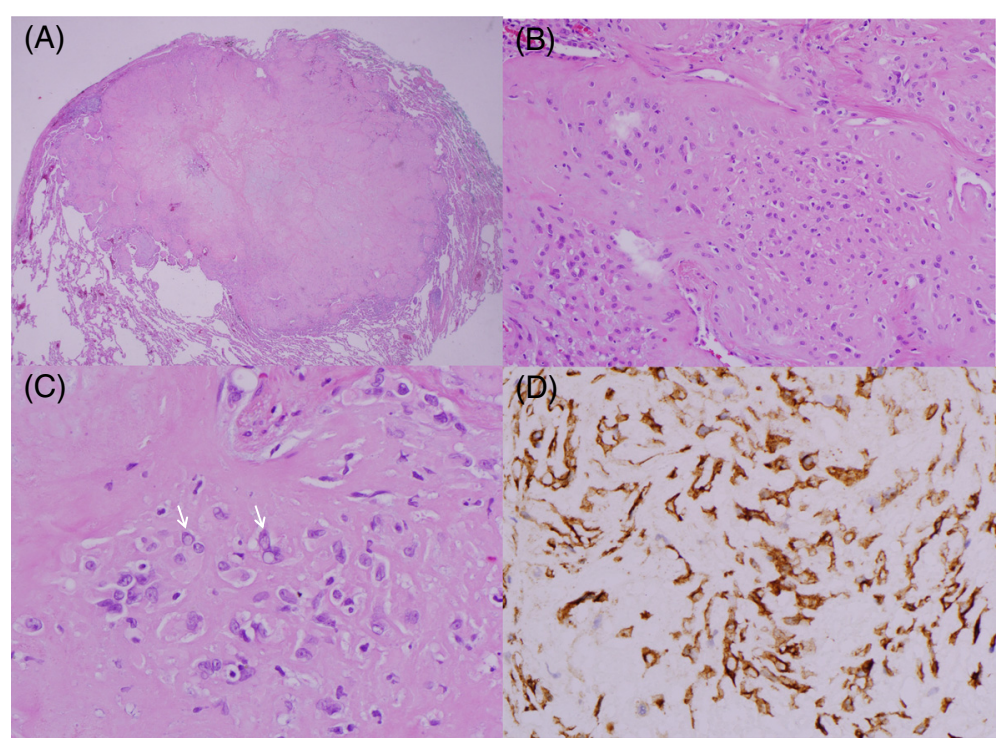

Figure 2 Pathological findings. (A) The nodule is well-demarcated, hyalinized, and within the lung parenchyma (hematoxylin and eosin, $\times 40$ ). (B) Variable-sized and irregularly shaped tumor cells with round to oval shape nucleus are located in the hyalinized stroma. Some of the neoplastic cells are rich in eosinophilic cytoplasm (×200). (C) There are characteristic intracytoplasmic vacuoles in the tumor cells (arrow; $\times 400)$. (D) The tumor cells are immunoreactive for CD31 in the cytoplasm ( $\times 400)$.

mainly achieved by pathological examination of the surgical biopsy and immunohistochemistry indicating diffuse factor VIII-related antigen cytoplasmic staining in the malignant cells, confirming an endothelial lineage for the tumor cells $[7,11]$. The other cell markers are CD31 and CD34 [12]. Owing to the low incidence of $\mathrm{PEH}$, there are no definite treatment guidelines. The prognosis of this tumor is unpredictable, with life expectancy ranging from 1 to 15 years [5]. The presence of metastatic lesions at the time of diagnosis does not correspond with a reduced survival [7]. However, pleural effusion has been shown to correlate with a poor survival [12]. Due to the unpredictable nature of the outcome, if possible, curative resection should be considered to maximize the possibility of a good outcome. Adjuvant radiotherapy is used to control residual disease for patients with localized epithelioid hemangioendothelioma. Chemotherapy with interferon- $2 \alpha$ or carboplatin plus etoposide is the preferred therapy for patients with widespread disease, but the benefits are unclear $[4,13,14]$.

Our patient's age was 50 years, which is somewhat older than the age at which patients typically present with PEH. He had bilateral pulmonary nodules and showed lobulated lesions without pleural thickening. Given the multiple small round pulmonary nodules, we considered metastatic nodules to be a possibility. From the results of the frozen biopsy analysis, we did not deem it necessary to resect all of the nodules; however, the final pathologic finding was indicated to be a $\mathrm{PEH}$, consecutive surgery was performed.

\section{Conclusions}

In conclusion, this case of PEH indicates the difficulty in diagnosing this rare tumor. Clinicians should be aware of the possibility of a low-grade malignancy, even if surgical frozen biopsy analysis indicates benign features.

\section{Consent}

The study was performed in accordance with the Declaration of Helsinki and Good Clinical Practice guidelines. The study was approved by the Institutional Review Board of Chonnam National University Hwasun Hospital. Written informed consent was obtained from the patient for publication of this case and for the accompanying images.

\section{Abbreviations}

CT: computed tomography; LUL: left upper lobe; PEH: pulmonary epithelioid hemangioendothelioma; RLL: right lower lobe; VATS: video-assisted thoracoscopic surgery.

\section{Competing interests}

The authors declare that they have no competing interests.

\section{Authors' contributions}

MAK collected data and drafted the manuscript. JSC and HYC conceived of the report and collected data. IJO supervised and corrected writing of the manuscript. YCK and CKP conceived of the report and revised the manuscript. JSY, SYS, and KJN operated the patient and contributed to conception. YDC supervised the pathology and managed the figures. All authors read and approved the final manuscript.

\section{Acknowledgements}

This study was supported by a grant (HCRI14017-1) Chonnam National University Hwasun Hospital Institute for Biomedical Science. We thank Craig Andrew Besas and Jera Mae Eluna, who provided English editing and proofreading. 


\section{Author details}

${ }^{1}$ Department of Internal Medicine, Chonnam National University Medical School, 671 Jebong-ro, Dong-gu, Gwangju 501-757, Republic of Korea. ²Lung and Esophageal Cancer Clinic, Chonnam National University Hwasun Hospital, 322 Seoyang-ro, Hwasun, Jeonnam 519-809, Republic of Korea. ${ }^{3}$ Department of Pathology, Chonnam National University Medical School, 671 Jebong-ro, Dong-gu, Gwangju 501-757, Republic of Korea. ${ }^{4}$ Department of Thoracic and Cardiovascular Surgery, Chonnam National University Medical School, 671 Jebong-ro, Dong-gu, Gwangju 501-757, Republic of Korea.

Received: 9 October 2014 Accepted: 23 February 2015

Published online: 14 March 2015

\section{References}

1. Geramizadeh B, Ziyaian B, Dehghani M, Tahmasebi K. Prolonged hemoptysis caused by primary pulmonary epithelioid hemangioendothelioma; a case report and review of the literature. Iran J Med Sci. 2014;39(2 Suppl):223-7.

2. Weiss SW, Enzinger FM. Epithelioid hemangioendothelioma: a vascular tumor often mistaken for a carcinoma. Cancer. 1982:50:970-81.

3. Kim EY, Kim TS, Han J, Choi JY, Kwon OJ, Kim J. Thoracic epithelioid hemangioendothelioma: imaging and pathologic features. Acta Radiol. 2011:1:161-6.

4. Dail DH, Liebow AA, Gmelich JT, Friedman PJ, Miyai K, Myer W, et al. Intravascular, bronchiolar, and alveolar tumor of the lung (IVBAT). An analysis of twenty cases of a peculiar sclerosing endothelial tumor. Cancer. 1983;1(51):452-64

5. Cronin P, Arenberg D. Pulmonary epithelioid hemangioendothelioma: an unusual case and a review of the literature. Chest. 2004;125:789-93.

6. Jang KY, Jin GY, Lee YC, Lee HB, Kang MJ, Choi MY, et al. Pulmonary epithelioid hemangioendothelioma: a tumor presented as a single cavitary mass. J Korean Med Sci. 2003;18:599-602.

7. Amin RM, Hiroshima K, Kokubo T, Nishikawa M, Narita M, Kuroki M, et al. Risk factors and independent predictors of survival in patients with pulmonary epithelioid haemangioendothelioma. Review of the literature and a case report. Respirology. 2006:11(6):818-25.

8. Gill R, O'Donnell RJ, Horvai A. Utility of immunohistochemistry for endothelial markers in distinguishing epithelioid hemangioendothelioma from carcinoma metastatic to bone. Arch Pathol Lab Med. 2009;133:967-72.

9. Lau K, Masssad M, Pollak C, Rubin C, Yeh J, Wang J, et al. Clinical patterns and outcome in epithelioid hemangioendothelioma with or without pulmonary involvement: insights from an internet registry in the study of a rare cancer. Chest. 2011;140:1312-8.

10. Schattenberg T, Kam R, Klopp M, Herpel E, Schnabel PA, Mechtersheimer G, et al. Pulmonary epithelioid hemangioendothelioma: report of three cases. Surg Today. 2008;38:844-9.

11. Rosengarten D, Kramer MR, Amir G, Fuks L, Berkman N. Pulmonary epithelioid hemangioendothelioma. Isr Med Assoc J. 2011;13:676-9.

12. Bagan P, Hassan M, Le Pimpec BF, Peyrard S, Souilamas R, Danel C, et al. Prognostic factors and surgical indications for pulmonary epithelioid hemangioendothelioma: a review of the literature. Ann Thorac Surg. 2006:82:2010-3.

13. Drazin D, Gandhi R, Slodkowska E, Boulos AS. Epithelioid hemangioendothelioma of the mastoid: resection for recurrence and adjuvant radiation with 8-year followup. Case Rep Surg. 2013;2013:469201.

14. Sardaro A, Bardoscia L, Petruzzelli MF, Nikolaou A, Detti B, Angelelli G. Pulmonary epithelioid hemangioendothelioma presenting with vertebra metastases: a case report. J Med Case Rep. 2014:8:201.

\section{Submit your next manuscript to BioMed Central and take full advantage of:}

- Convenient online submission

- Thorough peer review

- No space constraints or color figure charges

- Immediate publication on acceptance

- Inclusion in PubMed, CAS, Scopus and Google Scholar

- Research which is freely available for redistribution

Submit your manuscript at www.biomedcentral.com/submit 